\title{
EFFORT OF VARYING INTENSITY AS A FACTOR INFLUENCING THE VARIABILITY OF SELECTED BIOCHEMICAL BLOOD PARAMETERS OF JUMPING HORSES
}

\author{
HANNA BIS-WENCEL, KRZYSZTOF LUTNICKI ${ }^{1}$, AGNIESZKA ZOFIA ROWICKA, \\ BOŻENA NOWAKOWICZ-DĘBEK, AND MONIKA BRYL
}

\begin{abstract}
Department of Animal and Environment Hygiene, University of Life Science in Lublin, 20-950 Lublin, Poland,
${ }^{1}$ Department and Clinic of Animal Internal Diseases, University of Life Science in Lublin, 20-033 Lublin, Poland. hanna.biswencel@up.lublin.pl
\end{abstract}

Received: November 24, 2011

Accepted: April 27, 2012

\begin{abstract}
Blood samples were collected from horses in four time points of the spring-winter training season, according to the difference in effort intensity characteristic for each period. Serum contents of glucose, cholesterol, and creatinine, as well as activity of creatine kinase, aspartate and alanine aminotransferases, and alkaline phosphatase were determined. Training did not cause muscle damage, and as a result of training, changes in the characteristics of both, contraction and biochemical properties of muscle tissue took place, which was confirmed by the conducted tests.
\end{abstract}

Key words: jumping horses, training, blood biochemical parameters.

Intensive training of horses, on the border of their physical endurance, as well as extremely high effort during the races, can cause a number of pathological changes in the body, manifested in the form of so-called overtraining syndrome. It was noted that horses subjected to highly intensive training with short breaks for rest between training activity rounds achieve poor results. Unfortunately, the reasons for this situation are not sufficiently explained (7). For practical and cognitive reasons, the objective indicators of health and fitness, which could predict and monitor overtraining syndrome of horses, are sought (12). Unrecognised overtraining syndrome may be the cause of the withdrawal of these horses in the actual sport season. The biggest role in choosing the right training strategy plays the trainer's experience. Therefore, significant differences in the applied training programmes, which aim to prepare optimally the horse for competition and avoid injury during the preparation (training), are observed (2). Overtraining states are often intentionally caused in horses to determine the limits of adaptation, based on behavioural, morphological, and biochemical observations and pathological changes in the body of sport horses subjected to extreme effort $(2,12)$. Most of these studies relate to race horses and they are usually conducted on a track (12), while changes in the horse's body during the jump are rarely reported (2).
The aim of this study was to assess the impact of exercise of varying intensity on the variability of selected biochemical blood parameters in half-bred jumping horses.

\section{Material and Methods}

The study was conducted in the spring-winter season on 25 half-bred horses, 12 stallions and 13 mares, aged 3-11 years, competing in show jumping discipline. The horses were kept in individual stalls in the stables, on a bedding of straw, with constant access to running water. Average ration per day per one horse was $3.5 \mathrm{~kg}$ of hay twice a day, $5 \mathrm{~kg}$ of oats (two portions) and $60 \mathrm{~g}$ of vitamins $\mathrm{B}$ and $\mathrm{E}$ (Hipp Vital). During competitions, the horses were given extra feed $(1 \mathrm{~kg})$ in the form of muesli (Dynamix's Besterly), twice a day. The horses were subjected to a daily training programme, which included: $1 \mathrm{~h}$ - carousel, $10 \mathrm{~min}$ walk, $10 \mathrm{~min}$ - relaxed trot, $5 \mathrm{~min}$ - working trot, and 57 min-gallop. While participating in competitions, the training plan included an additional $1 \mathrm{~h}$ of lunging and 1 $\mathrm{h}$ of riding (under saddle) before noon. The horses were under constant veterinary supervision and were subjected to prophylactic treatment, according to a programme applicable for this species.

Blood samples were collected four times: in early March, when the indoor season was nearing to the 
end (a smaller number of starts), in late May, when an effort was particularly intensified due to the continuous training, the start of the open season and more competitions, in October after moderate exercise training, and in early December (the next indoor season). Blood was taken from the external jugular vein to dry tubes, in a closed system , always in the morning, before feeding and watering. Serum contents of glucose (GLUC), cholesterol (CHOL), and creatinine (CREA), as well as activity of creatine kinase (CK - EC 2.7.3.2), aspartate aminotransferase (AST - EC 2.6.1.1), alanine aminotransferase (ALT - EC 2.6.1.2), and alkaline phosphatase (ALP - EC 3.1.3.1) were determined. The tests were performed using the analyser 130 and a set of BS's Cormay reagents.
The obtained results are presented as arithmetic means and standard deviations (SD). The significance of differences between mean values were calculated using Student's $t$ test for dependent variables (Microsoft Office Excel 2007) taking the statistical significance limit at $\mathrm{P}<0.05$.

\section{Results}

Mean values of biochemical blood indicators are presented in Table 1 . The levels of the examined parameters (with the exception of creatinine) were located in the reference values adopted for this species (13) in all studied periods.

Table 1

The mean values of blood biochemical parameters of training horses.

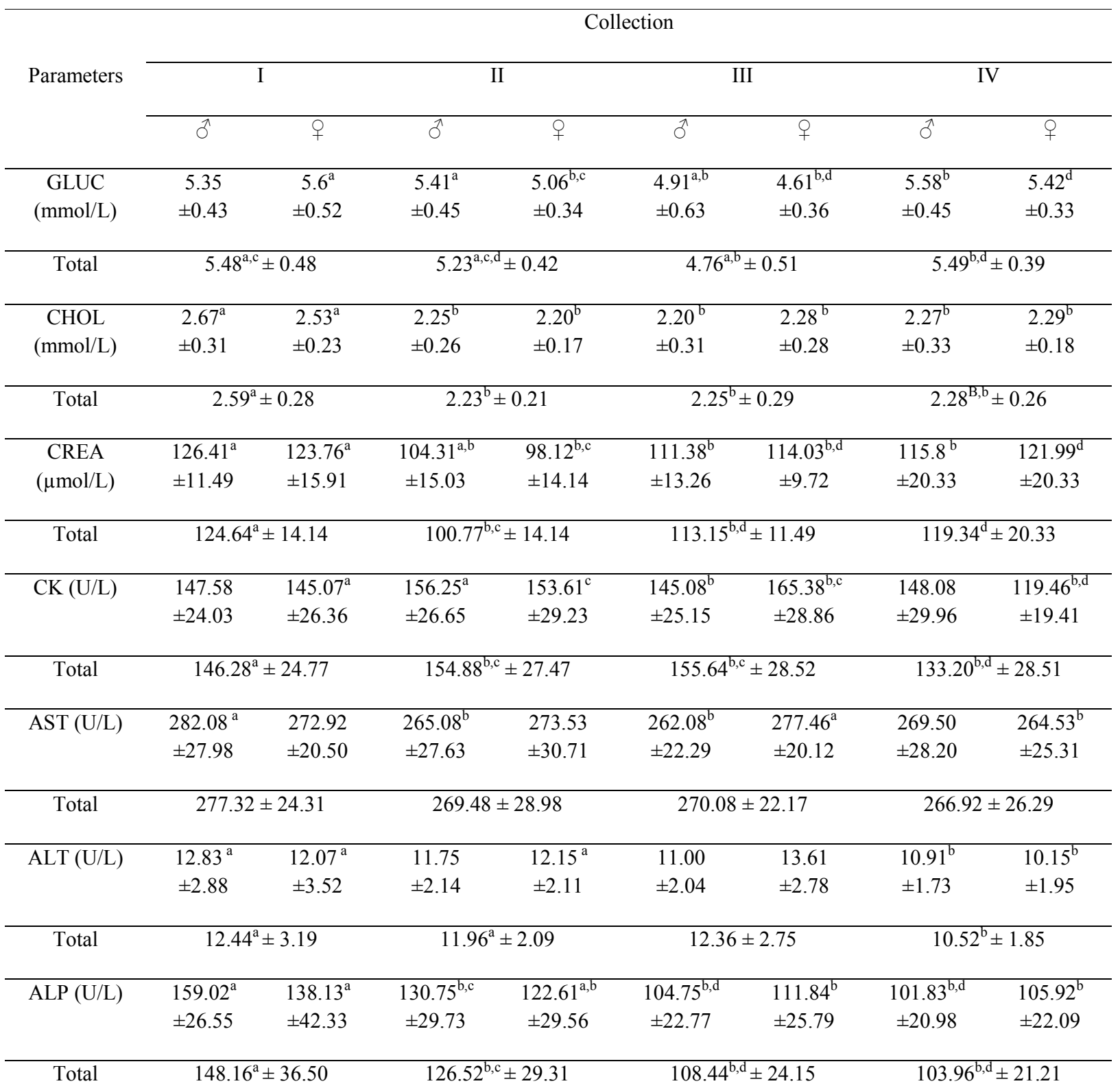

a, b, c - P<0.05; GLUC - glucose, CHOL - cholesterol, CREA - creatinine, AST - aspartate transaminase , ALT - alanine aminotransferase, ALP - alkaline phosphatase, CK - creatine kinase; \pm SD 
Glucose concentrations in all horses maintained at balanced level (5.23-5.49 $\mathrm{mmol} / \mathrm{L})$, with the exception of the collection III in which there was a slight decrease $(4.76 \mathrm{mmol} / \mathrm{L})$, statistically significant in comparison to the collections II $(\mathrm{P}<0.05)$ and IV $(\mathrm{P}<0.05)$ in stallions. In mares, a statistical significance of differences $(\mathrm{P}<0.05)$ between collections (except I and IV) was reported.

Total cholesterol in stallions remained at a balanced level, with a small downward trend, taking the average values from 2.20 to $2.67 \mathrm{mmol} / \mathrm{L}$. A decrease, followed by an increase in this parameter (2.20 - $2.29 \mathrm{mmol} / \mathrm{L})$, was also observed in mares in the collection II. Statistically significant differences $(\mathrm{P}<0.05)$ were noted between the collections I and II, I and III, as well as between I and IV.

The highest values of creatinine in stallions and mares were recorded in the collection I, with an average intensification of effort (stallions 126.41, mares $123.76 \mu \mathrm{mol} / \mathrm{L}$ ) and the lowest in the collection II, when the effort was characterised by very high intensity (stallions 104.31, mares $98.12 \mu \mathrm{mol} / \mathrm{L}$ ). Statistically significant differences $(\mathrm{P}<0.05)$ were observed between the collections I and II, I and III, and II and IV in stallions, as well as between the collections I and II, II and III , and II and IV and I and III in mares.

The highest creatine kinase activity was observed in stallions in the collection II and in mares in the collection III. The level of this enzyme in mares showed an upward trend in the third intake (which recorded the highest value of this parameter 165.38 U/L), and then was reduced in the collection IV. Statistically significant differences $(\mathrm{P}<0.05)$ were observed between the collections II and III in stallions, and between the collections I and III, I and IV, II and IV, and III and IV in mares.

Average AST activity in the collections II and III showed a downward trend but in the collection IV a slight increase in AST activity (269.5 U/L) was found. Statistically significant differences were not observed. There was a statistically significant $(\mathrm{P}<0.05)$ increase in AST activity in the collections II and III in mares, reaching $277.46 \mathrm{U} / \mathrm{L}$ in the collection III. Statistically significant differences were recorded between the collections I and II, and I and III $(\mathrm{P}<0.05)$ in stallions.

In presented study, alkaline phosphatase activity was characterised by a downward trend between all four collections. In mares statistically significant differences occurred between the collections I and II and I and III, and between I and IV and II and IV $(\mathrm{P}<0.05)$, and in stallions between all collections except III and IV $(\mathrm{P}<0.05)$.

The highest average ALT activity in horses was observed in the collection I (12.44 U/L). In stallions, the decline of this parameter occurred in subsequent collections, while the growth was noted in mares, with the exception of the collection IV. Statistically significant differences $(\mathrm{P}<0.05)$ were observed between the collections I and IV in both sexes and between II and IV in mares.

\section{Discussion}

The glucose content, whose blood level is fairly stable, is a good indicator of energy economy; however, some fluctuations associated with the emotional state, or after a meal are observed. In case of resting sport horses the blood glucose usually varies from 5.0 to $6.5 \mathrm{mmol} / \mathrm{L} \quad$ (9). The content below 4 $\mathrm{mmol} / \mathrm{L}$ may indicate pathological conditions, improper nutrition, overstrain, or may be one of the first signs of overtraining (9). In this study, the obtained results are in agreement with researches carried out on the Arabian horses in race training by Kędzierski $5.76 \mathrm{mmol} / \mathrm{L} \quad$ (6), Szarska $-5.7 \mathrm{mmol} / \mathrm{L} \quad$ (10), and Winnicka $-3.1-6.2 \mathrm{mmol} / \mathrm{L}$ (13). However, the value of this parameter changed both: during exercise and after its completion. The growth of glucose concentration in healthy horses is one of the symptoms of increased sympathetic nervous system activity and is proportional to the intensity of effort and the level of lactate in blood (3). Under the influence of increased levels of adrenaline in the peripheral circulation, glucose is released to blood from liver glycogen, while muscles have a limited capacity for the glucose absorption and utilisation (6). The process of glucose absorption by muscle fibres with high concentrations of both glucose and insulin (after a meal) is fast. Plasma glucose and insulin concentration decreases during exercise and muscle use glycogen reserve (8). An increase in the concentration of blood glucose after exercise and long-term return to resting values provides a high work-load for the organism (6). Maintaining blood glucose level during exercise depends on the size of glycogenic liver resources and the activation of gluconeogenesis. Usually in the first stage of effort in horses during sporting events, a decrease in glucose and then its growth is observed. The size of changes depends on the degree of the body preparation to the effort and speed of the utilisation of carbohydrate reserves as well as on the type and intensity of effort. There is a different demand for glucose in the short but very intensive efforts - for example race, and during long distance races, where the primary energy substrates are free fatty acids. Thanks to the increasing participation of the fatty acids mechanisms in the metabolism of effort, the body has the possibility of saving carbohydrates (10). With prolonged work, the share of fatty acids in the overlapping energy needs is increasing, and the increase is inversely proportional to the intensity of the effort (4). In short effort lasting from $30 \mathrm{sec}$ to $10-15 \mathrm{~min}$, the main energy substrate is muscle glycogen, which provides glucose in the process of glycogenolysis. During a maximum intensity effort after 3-4 min, the highest concentration of lactate in muscle cells is observed $(3,4)$.

As a result of regularly performed physical activity, the level of HDL lipoprotein increases. It is accompanied by the reduction in the levels of VLDL lipoprotein fractions, as well as in the total cholesterol and the rich in triacylglycerols and lipoproteins LDL fractions in the blood. The correct reference values of total cholesterol in horses vary from 1.3 to 2.8 
$\mathrm{mmol} / \mathrm{L}(13)$, but the mechanism of the physical activity impact on the changes of lipid levels in blood is not yet fully explained. It is not excluded that physical training stimulates the synthesis of cholesterol precursors in the liver and intestines and increases tissue sensitivity to insulin. This results in reduced release of free fatty acids (insulin inhibits this process) and reduced production of VLDL lipoprotein fractions in the liver (3). In studies (7) carried out on horses subjected to moderate and intense effort, cholesterol and glucose levels were similar in both groups of trained horses (GLUC 4.64 and 4.99 and CHOL, 1.85 and $\quad 1.88 \mathrm{mmol} / \mathrm{L}), \quad$ but lower compared with the present research.

The concentration of creatinine in the blood is the result of metabolism. It depends directly on muscle mass and the efficiency of renal function. One of the factors that increase the production of creatinine is physical effort (6). In the presented studies, mean serum creatinine concentrations of individual collections were placed below the reference values (106.1$167.9 \mu \mathrm{mol} / \mathrm{L})$ (13), similarly to the results obtained by Padalino et al. (7) $-119.34 \mu \mathrm{mol} / \mathrm{L}$. Despite the statistical significance, the fluctuations did not reflect the negative impact of increased effort.

Creatine kinase is a key enzyme indicating irregularity in the muscular system function. The CK increases in serum most commonly due to muscle damage, prolonged physical exertion, as well as certain organs damage $(5,13)$, and is directly proportional to the degree of skeletal muscle damage (10). Finding a permanent increase in $\mathrm{CK}$ activity suggests undertaking a decision to reduce the exercise intensity of the sports horses. The highest exertional kinase increase is observed in racing horses, in which the average resting blood CK levels are significantly higher compared to jumping horses (166.4 U/L), eventing horses $(168.4 \mathrm{U} / \mathrm{L})$, and pure blood race horses $(170.0 \mathrm{U} / \mathrm{L})(2$, $10,11)$. In the interpretation of CK activity, the animal's clinical status, pathological symptoms, and stage of training should be included. Two-threefold increase in CK relative to its resting value may occur without any clinical symptoms and may indicate the beginning of muscle damage. Fluctuations of this parameter may also indicate that the conducted training has caused a stronger response from the muscle tissue. The second collection from stallions in the present study showed the highest increase in CK activity. It can be concluded that there was a tendency of a higher level of muscle fatigue in stallions than mares. Creatine kinase activity decreased during the last collection in mares and there were no noticeable muscle injuries. Still a satisfactory and complete explanation of individual differences in CK response to exercise is not known (8). In the available literature, the authors give different values of $\mathrm{CK}$ as normal in horses - from 90$565 \mathrm{U} / \mathrm{L}$ to $166-230 \mathrm{U} / \mathrm{L}(10,13)$.

Muscle fibers are composed of actin and myosin myofibrils, with a diameter of 1-3 $\mu$. Within the myofibrils repeated episodes of varying degrees of light refraction (anisotropic and isotropic) can be seen. The segments forming the anisotropic heavy myofilaments consist of myosin, while forming a thin isotropic sections are constructed primarily of actin (3). ATP is used by myofilaments (thick) and as a result of its hydrolysis, ADP is formed. Creatine is used as a transporter of phosphate groups and the CK takes phosphate group of ATP, which then joins the creatine. It also carries a phosphate group from phosphocreatine back to ADP (ATP reproducing) $(8,3)$. According to the prevailing opinion, the phosphocreatine is an energy source only during short-term efforts of high intensity or during the transition from rest to exercise. It also serves an important function of the phosphate group's transporter in the highly-energy bonds (8).

Alkaline phosphatase is present in the cell membranes of many tissues. It is an enzyme, found mainly in the bones, liver and intestine, essential for the mineralisation and transformation of organic phosphates. Variability in serum ALP activity may reflect the activity of osteoblasts (7). The obtained results were within the lower limits of reference values 109-315 U/L (13) and were lower than results obtained by Padalino et al. (7) in horses undergoing moderate and intense workout-293.12 and $345.73 \mathrm{U} / \mathrm{L}$. The authors reported significantly higher levels of enzymes such as CK -166.35 and 284.5 U/L, AST - 325.5 and 510.7 U/L, and ALP 293.12 and $345.73 \mathrm{U} / \mathrm{L}$ in the group of horses subjected to a very intensive effort in relation to horses less burdened by effort. This indicates a better training adaptation than in the case described above. Overtraining leads to muscle fatigue manifested by increased enzyme activity, and significant differences in ALP activity in the intensively used horses. It can be also a sign of disorders resulting from intense exercise (7).

Alanine aminotransferase is an intracellular enzyme, and its activity should be in the range from 3.0 to $25.0 \mathrm{U} / \mathrm{L}$ (13). The highest concentrations of ALT occur in the liver, lower in skeletal muscles, myocardium, and kidneys. The appearance of elevated enzyme activity in plasma indicates cell damage, and its growth is dependent on the type and extent of the damage (10). Values obtained in this paper regarding ALT activity during various intensity of training were similar to those of other authors: $10.65 \mathrm{U} / \mathrm{L}$ lower intensity, $13.90 \mathrm{U} / \mathrm{L}$ - higher intensity (7), and 13.94 U/L - lower intensity, 14.06 U/L - higher intensity (1).

Short-term changes in the CK, AST, and ALT levels might be caused by great effort, and sometimes may be the first symptom of overtraining. In that case, the elevated level of ALT is accompanied by the increase in CK activity. Under normal conditions, serum AST activity in horses should not exceed $300 \mathrm{U} / \mathrm{L}$ (10). Elevated activity of AST may also (in addition to skeletal muscle overload) result from cardiac overload and liver dysfunction.

The main feature of skeletal striated muscle tissue is its plasticity, reflected by their ability to adaptation to different loads of effort. As a result of training, changes in the characteristics of both, 
contraction and biochemical properties of muscle tissue are made in such a direction, that the muscle works in an optimal way. Training improves the specificity of activity, and the precision and harmony of the move. The consequence of training is lower effort energy expenditure, and the unmistakable effect is the economisation of energy expenditure (3). Beneficial adaptive changes obtained during training are retreated as a result of its omission or in case of stagnation (8). Our study shows that the average values of biochemical blood parameters of horses are placed within the range of accepted values for this species during the experiment. In mares the values were relatively higher compared to stallions. The elevated levels of creatinine and AST after a moderate training exercise period were the only exceptions (collection III).

\section{References}

1. Bis-Wencel H., Saba L., Wnuk W., Nowakowicz-Dębek B., Krzyszycha J.: Evaluation of mineral levels in the trophic system with regard to activity of select enzymes in horses' blood serum before and during intensive activity period. Medycyna Wet 2002, 58, 881-883.

2. Jawor P., Stefaniak P., Borkowski J., Przewoźny M., Wierzbicki H., Swagemakers J.H.: Utility of selected blood parameters in monitoring the accuracy of show jump horse training. Medycyna Wet 2007, 63, 213-218.

3. Jones E.W.: Exercise physiology research. J Equine Vet Sci 2003, 3, 129.
4. Kaneko J.J., Harvey J.W., Bruss M.L. Clinical biochemistry of domestic animals. San Diego, Academic Press 1997, pp. 407-440.

5. Krumrych W.: Wskaźniki laboratoryjne krwi koni wartości referencyjne i interpretacja. Editor National Veterinary Research Institute, Pulawy, Poland, 2007.

6. Kędzierski W.: Effect of intense exercise on selected haematological and biochemical blood parameters of Arabian horses. Acta Sc Pol Med Vet 2005, 4, 113-119.

7. Padalino B., Rubino G., Centoducati P., Petazzi F.: Training versus overtraining: evaluation of two protocols. Equine Vet J Sci 2007, 27, 28-31.

8. Piccione G., Casella S., Giannetto C., Messina V., Monteverde V., Caola G., Guttadauro S.: Haematological and biochemical responses to training and competition in standard bred horses. Comp Clin Pathol 2010, 19, 95-101.

9. Szarska E.: Assessment of exercise capacity of horses on the basis of changes in selected blood parameters tested at rest, after exercise and after a period of restitution. Medycyna Wet 1990, 46, 452-453.

10. Szarska E.: Wykorzystanie badań diagnostycznych krwi do oceny stanu zdrowia i zaawansowania treningowego koni wyczynowych. Editor SGGW, Warszawa, 2002.

11. Szarska E.: Investigations of blood parameters for evaluating health status and training effects in race and sport horses (in Polish). Zesz Nauk AR Wroclaw, 471. Rozprawy CCIII. Editor AR Wroclaw, 2003.

12. Tyler C.M., Golland L.C., Evans D.L., Hodgson D.R., Rose R.J.: Haematological and biochemical responses to training and overtraining. Equine Vet $\mathrm{J}$ Suppl 1991, 31, 621-625.

13. Winnicka A.: Wartości referencyjne podstawowych badań laboratoryjnych $\mathrm{w}$ weterynarii. Editor SGGW, Warszawa, 2008. 